Revista Eletrônica do Mestrado em Educação Ambiental

Programa de Pós-Graduação em Educação Ambiental

\title{
Contribuições da Educação Ambiental para o desenvolvimento comunitário local na Ilha do Mel (Paraná)
}

\author{
Vanessa Marion Andreoli ${ }^{1}$ \\ Marília Andrade Torales Campos ${ }^{2}$
}

Resumo: O artigo discute possíveis contribuições da Educação Ambiental nos processos de desenvolvimento de comunidades, voltando-se para as práticas pedagógicas dos professores que atuam nos colégios estaduais do campo localizados no entorno das Unidades de Conservação da Ilha do Mel/PR. Com o objetivo de analisar a relação entre a Educação Ambiental, o currículo e o desenvolvimento comunitário local, a pesquisa foi construída a partir da metodologia da triangulação de dados tanto para a coleta quanto para a análise, qualitativa e dialética da realidade. Como principais resultados, aponta-se que os professores, apesar de envoltos por diversas e complexas problemáticas como a alta rotatividade docente e precárias condições de trabalho, tendem a valorizar a cultura, os saberes e a natureza da Ilha na sua prática pedagógica de Educação Ambiental.

Palavras-chave: Educação Ambiental; Currículo; Desenvolvimento comunitário local.

\section{Contributions of Environmental Education to local community development in Ilha do Mel (Paraná)}

\begin{abstract}
The article discusses possible contributions of Environmental Education in the processes of community development, turning to the pedagogical practices of teachers who work in state camp colleges located around the Conservation Units of Ilha do Mel/PR. With the objective of analyzing the relationship between Environmental Education, curriculum and local community development, the research was constructed from the methodology of data triangulation both for the collection and for the qualitative and dialectical analysis of reality. As main results, it is pointed out that teachers, despite being surrounded by diverse and complex problems such as high teacher turnover and precarious work conditions, tend to value the culture, knowledge and nature of the Island in its pedagogical practice of Environmental Education.

Keywords: Environmental Education; Curriculum; Local community development.

\footnotetext{
1 Professora da Universidade Federal do Paraná - Setor Litoral. Doutora em Educação, Mestre em Sociologia, Especialista em Educação, Meio Ambiente e Desenvolvimento e Pedagoga. E-mail: vanessaandreoli.ufpr@gmail.com ${ }^{2}$ Professora da Universidade Federal do Paraná. Doutora em Ciências da Educação. Mestre em Educação e Pedagoga. Email: mariliat.ufpr@gmail.com
}

Rev. Eletrônica Mestr. Educ. Ambient. Rio Grande, Edição especial XVI Encontro Paranaense de Educação Ambiental, p. 132-149, set. 2017. E-ISSN 1517-1256 


\section{Introdução}

É fato que a exploração desenfreada da natureza tem forte vínculo com o modelo de organização social adota por diversas sociedades. No caso da sociedade capitalista, o desenvolvimento possibilitou o progresso e o bem-estar material de uma pequena parcela de seres humanos, mas também foi - e continua a ser - a causa de profundos desequilíbrios sociais e ambientais. É possível dizer, portanto, que a crise ambiental que vivenciamos é sinônimo da crise das relações sociais (GÓMEZ; FREITAS; CALLEJAS, 2007; SAUVÉ, 2005; TREIN, 2012, entre outros). Nesse sentido, emerge do contexto o referente da escola como espaço de político e de lutas sociais, que demanda uma articulação com a produção de sentido de práticas pedagógicas educativas que reforcem um sentimento de corresponsabilização e constituição de valores éticos e comunitários. Esta tessitura nos provoca a pensar em estratégias que possam fortalecer o papel político da escola e também da Educação Ambiental, tendo em vista que há um grande potencial de vinculação entre a escola e a sociedade.

De início, cabe esclarecer que a Educação Ambiental que se discutiu no contexto desta pesquisa parte de uma perspectiva crítica, já que tem seu ponto de partida na interpretação da realidade social da sociedade capitalista, compreendendo a educação como reprodutora das relações sociais (SAVIANI, 2003; TREIN, 2012), a escola como uma construção social (LOPES 1999; BRANDÃO, 1981) e o currículo como um território em constante disputa de interesses (ARROYO, 2013). É importante destacar que a Educação Ambiental, quando proporciona uma formação emancipatória que permita a participação dos sujeitos nos processos decisórios e, consequentemente, seu fortalecimento, pode potencializar possíveis transformações com vistas a melhoria de suas condições de vida.

No caso dos povos do campo no Brasil, as desigualdades sociais e a defasagem histórica em relação ao acesso e permanência à educação (CALDART, 2012; ARROYO, 2013; DIEGUES, 1992), resultou em uma massificação das escolas nessas regiões que apresentam condições precárias e nas quais vinculam valores agregados que não condizem com a cultura das comunidades. Nesse contexto, a Educação do Campo é um processo de luta histórica desencadeada pelos movimento sociais do campo que visa incidir sobre a política de educação a partir de interesses sociais das comunidades do campo (CALDART, 2012). Sendo assim, é um campo bastante específico, já que se fundamenta prioritariamente na associação com as questões do desenvolvimento e do território no qual 
está enraizado. Nesse sentido, como prática social em construção, se caracteriza como uma luta por uma educação específica para e com as comunidades do campo.

A precariedade da situação dos povos do campo se intensifica quando a transferimos para as peculiaridades vividas pelas populações que estão no entorno das Unidades de Conservação e, ainda, em ilhas. Em relação as Unidades de Conservação, a ideia inicial para criação no Brasil, importada dos Estados Unidos, era a de preservar intactos locais que apresentassem grande beleza cênica que os seres humanos pudessem apreciar, como se fossem "antídotos" (DIEGUES, 2010) para solucionar parte da crise ambiental que já era debate emergente. O que não se discutia era o fato de que, principalmente nos países subdesenvolvidos, esses locais que aparentemente eram desabitados, muitas vezes escolhidos essencialmente em função apenas de seus atributos naturais estéticos, eram ocupados por povos tradicionais portadores de uma outra cultura, que geralmente eram pobres e dependiam majoritariamente para sua sobrevivência dos recursos naturais locais.

Nesse sentido, no Brasil essa situação fez com que os modos de vida das populações residentes nessas áreas ficassem de certa forma interditados. Agravadas pela falta de um plano de manejo coerente com suas demandas, necessidades e interesses (PIERRI; KIM, 2008), a realização de atividades econômicas e culturais costumeiras foram rigorosamente proibidas. O quadro de pobreza, assim, se intensifica e as populações vão sendo cada vez mais desprezadas enquanto sujeitos enunciadores de saberes e maneiras próprias de viver.

Em relação a especificidade das ilhas, elas apresentam, de maneira geral, fragilidades do ambiente natural que são potencializadas quando relacionadas a formas inadequadas de uso dos recursos e a poluição (DIEGUES, 1992). Assim, são altamente suscetíveis a degradações ambientais e apresentam dificuldades de recuperação parcial. Nesse sentido, Telles (2007, p. 1) ressalta que determinadas regiões apresentam-se em estágio de comprometimento ambiental eminente, fato que pode prejudicar "de maneira sistêmica os elementos relacionados ao ambiente natural e cultural, à atividade econômica e principalmente às questões relacionadas às comunidades tradicionais".

A partir desse olhar, o presente estudo voltou-se para a Ilha do Mel/PR, região considerada a maior atração turística do litoral do Paraná. A Ilha tem 95\% de sua área definida como Unidade de Conservação de Proteção integral. A Ilha passa por um momento de problemáticas socioambientais evidentes (TELLES, 2007). Aliada a intensa e desordenada ocupação e uso do solo, por conta da exploração turística e especulação 
imobiliária, a implantação das Unidades causaram forte impacto sobre as atividades econômicas tradicionais (pesca e roça artesanal) das comunidades caiçaras nativas e além disso consolidou o turismo como a principal atividade econômica do local.

A essa problemática somam-se também a falta de fiscalização nas ações restritivas, a não consideração das comunidades nos processos decisórios e a defasagem educacional da Ilha (precariedade das condições no que se refere a oferta, acesso e qualidade). Essa situação intensifica a pobreza dos nativos, já que, além de serem privadas dos seus modos de vida, as comunidades não são as principais beneficiadas com a criação das Unidades. Atualmente, é possível afirmar, portanto, que é uma região de vulnerabilidade socioambiental (WITT, 2013; TELLES, 2007; PIERRI; KIM, 2008, entre outros) e educacional (ANDREOLI, 2016) que merecem especial atenção, uma vez que a conservação dos recursos naturais está diretamente relacionada as questões sociais dos sujeitos.

Compreendendo que a Educação Ambiental pode contribuir no processo de fortalecimento das comunidades, na perspectiva da transformação social, quando a escola considera sua dimensão comunitária, a pesquisa de doutorado foi realizada com professores que atuam nos dois colégios estaduais da região e partiu da questão central: Quais são as possíveis relações entre Educação Ambiental, Currículo e Desenvolvimento comunitário local? Desta, derivaram outras mais específicas, tais como: Como as práticas pedagógicas de Educação Ambiental vem sendo desenvolvidas nos colégios? O fato de viver no entorno de uma Unidades de Conservação chega a escola? De que maneira? Quais são os desafios, no caso pesquisado, para que a Educação Ambiental contribua com o desenvolvimento comunitário local?

Como recorte para esse artigo, optou-se por discutir especificamente quais são as contribuições que a Educação Ambiental pode trazer para o desenvolvimento comunitário local da região, focando nos desafios colocados a prática pedagógica cotidiana dos docentes. Nesse sentido, busca-se apontar elementos que nos façam compreender a relação, possível e necessária, entre a Educação Ambiental, que é uma educação que tem potencial para contribuir na transformação da realidade e dos valores vinculados socialmente (LOUREIRO, 2012; TREIN, 2012; SAUVÉ, 2016; entre outros); o Currículo, que é uma forma concreta de possibilidades de mudança (TORALES-CAMPOS, 2013; TRISTÃO, 2007; VASCONCELLOS, 2011; entre outros), à partir da instrumentalização (SAVIANI, 2003) necessária para a emancipação dos sujeitos e superação das desigualdades sociais e degradação ambiental atuais, e o Desenvolvimento comunitário local, compreendido como 
uma das possibilidades reais para que as comunidades possam efetivamente repensar a dinâmica da qual fazem parte, ressignificando-a e modicando sua qualidade de vida (GÓMEZ; FREITAS; CALLEJAS, 2007; CARVALHO, 2002).

\section{A Educação Ambiental, o Currículo e o Desenvolvimento comunitário local}

É importante que se compreenda que, no âmbito dessa pesquisa, "desenvolvimento" não é visto como sinônimo de "crescimento econômico", mas abrange outras dimensões sociais (cultural e política) além da econômica. Seu objetivo é, num sentido mais amplo, a superação da realidade desigual que vivenciamos. Em outras palavras, significa a "transformação das sociedades predatórias - ambiental e socialmente - organizadas sob o modo capitalista de produção, em sociedades sustentáveis, social e ambientalmente" (TOZONI-REIS; CAMPOS, 2014, p. 159). O desenvolvimento é portanto sinônimo de mudança social e em seu cerne está a prática social dos sujeitos: quase como um desejo inato e intuitivo por uma vida melhor, a busca pelo desenvolvimento faz parte, portanto, da natureza humana (GÓMEZ; FREITAS; CALLEJAS, 2007; SAVIANI, 2003) e nesse sentido ele pode ser considerado sinônimo de mudança social.

Entretanto, é importante que se compreenda que, da maneira como se deu a relação entre o desenvolvimento e os usos dos recursos naturais ao longo do desenvolvimento das sociedades capitalistas, negou-se que As relações humanas, sócio-historicamente instituídas, não se
estabelecem exclusivamente em função de interesses práticos imediatos
como aqueles que se desenvolvem na mediação homem-natureza
(técnica), mas também num campo de relações intersubjetivas que é
mediado simbolicamente (relação homem-homem).
(PORTO-
GONÇALVES, 2008, p. 95)

A partir desta afirmativa, é possível compreender a crise socioambiental não como uma simples consequência do crescimento econômico, mas fruto das próprias contradições no interior da sociedade, ou, em outras palavras, dos próprios conflitos que estão no cerne das relações sociais instauradas na sociedade capitalista. $\mathrm{O}$ autêntico desenvolvimento não se refere apenas a satisfação das necessidades básicas, mas abarca também o aumento dos níveis de vida, ou seja, de educação, de cultura, de trabalho, de lazer, etc. e, além disso e talvez mais importante no contexto de se desenvolver uma nova racionalidade em relação ao desenvolvimento, se refere as condições de emancipação e liberdade dos sujeitos.

O "bom desenvolvimento" (GÓMEZ; FREITAS; CALLEJAS, 2007, p. 82), portanto, deve considerar tanto a conservação da natureza e da diversidade em todas as

Rev. Eletrônica Mestr. Educ. Ambient. Rio Grande, Edição especial XVI Encontro Paranaense de Educação Ambiental, p. 132-149, set. 2017. E-ISSN 1517-1256 
suas dimensões quanto o bem-estar humano. Nessa linha de pensamento, destaca-se o estudo de Pierri e Kim (2008), que procurou mostrar que a efetiva conservação das áreas de preservação ambiental, como é o caso da Ilha do Mel, depende da sustentabilidade social que, segundo as autoras, pode ser construída a partir de um desenvolvimento econômico que beneficie ambos os lados: a comunidade local e a preservação da natureza.

Frente a diversidade de contextos e realidades, há "desenvolvimentos" que contradizem a visão dominante, unilateral e parcial, que impõe apenas um modelo. Atualmente, os modelos alternativos de desenvolvimento se tencionam radicalmente a partir de duas lógicas (CARVALHO, 2002, p. 123): uma defende a manutenção e expansão dos modelos que já existem que nessa visão possibilitam "lapidar os recursos naturais do planeta com doses de capitalismo humanizado", e uma que busca transformar esses modelos existentes e principalmente sua forma de produção e consumo, "em programas ecologicamente prudentes e economicamente viáveis para todos".

Aqui surge o Desenvolvimento comunitário local como um dos modelos fundamentais na melhoria da qualidade de vida das comunidades e das gerações futuras (GÒMEZ; FREITAS; CALLEJAS, 2007; CARVALHO, 2002). Ele é local porque se desenvolve em comunidades com características peculiares e problemas específicos (território concreto e definido), e comunitário porque se trata de um desenvolvimento no qual participam os sujeitos membros da comunidade de forma ativa, determinada e auto organizada.

Condição fundamental para este tipo de desenvolvimento é a participação. Ao compreender que participar é a autopromoção dos sujeitos e o meio para a concretização da cidadania em suas múltiplas dimensões, pode-se dizer que ela seria a negação direta das práticas pedagógicas assistencialistas e paternalistas, calcadas nas ideias neoliberais. Participar é, portanto, fortalecer os sujeitos para atuarem em prol de interesses e necessidades comunitárias. Deve ser vista para além da oportunidade de decisões coletivas, como direito de usufruto tanto dos bens materiais como culturais. Em outras palavras, significa "dar poder às pessoas e dotá-las dos meios materiais e intelectuais suficientes para exercer esse poder a favor do bem-estar geral" (GÓMEZ; FREITAS; CALLEJAS, 2007, p. 87).

A Educação Ambiental, nessa perspectiva, tem como desafio construir uma identidade que possa trazer significado ao ser no mundo, possibilitando um pertencimento ao meio de vida e promovendo uma cultura do engajamento. Nesse sentido, o pertencimento ao lugar é condição necessária para a responsabilidade ambiental. Em nível 
das comunidades, ela pode potencializar dinâmicas sociais que favoreçam a solidariedade, numa perspectiva colaborativa e crítica das realidades (SAUVÉ, 2016).

Ao compreender que o ser humano, como ser social, histórico e inacabado é constituído socialmente na relação consigo mesmo, com os outros e com a natureza, é possível então afirmar que ele constitui-se na dinâmica cultural da qual faz parte: ao modificar o ambiente também se modifica (FREIRE, 1979; 1981). Dita de outra forma, além dos estímulos que recebem do meio ambiente, os seres humanos também transformam a natureza de acordo com as relações que vão estabelecendo entre si e das necessidades que vão criando de acordo com o pensamento predominante de cada época histórica. Nas palavras de Porto-Gonçalves (2008, p. 94), o ser humano não vai somente se adaptando aos diversos ecossistemas, mas, "moldando-os a ele, em virtude das suas necessidades histórico culturalmente desenvolvidas".

A escola, que tem espaço privilegiado na vida dos estudantes e de suas famílias, pode ser vista como um dos diversos agentes promotores de desenvolvimento. Nessa perspectiva, pode ser vista como um "centro de observação social", como sugere Carvalho (2002): ela nos permite observar, analisar, refletir e propor soluções que contribuam para o desenvolvimento local, já que, além de ser um privilegiado de participação na vida das comunidades, tem relativa autonomia em relação as demais instituições que compõe as dinâmicas comunitárias. É importante, nesse contexto, que se tenha convicção de que não se trata de pensar que mudando a escola automaticamente se muda também a sociedade, porque na sociedade capitalista a base da mudança está nas relações sociais de produção que interferem e definem o tipo de educação que ocorre nas instituições educacionais. Nesse sentido, a educação é algo muito mais abrangente e embora a escolarização seja importante e seja vista como a instituição oficial que oferta educação, ela é apenas um dos tempos e espaços da formação humana.

A relação entre o currículo e a prática pedagógica nas escolas não se dá de maneira mecânica, mas o primeiro influencia diretamente o segundo, já que sua força está nos detalhes que compõe o cotidiano: nos tempos (horários e duração das aulas, calendários, divisão das classes por séries, tempos de vivências significativas, etc.) e nos espaços (disciplinas, distribuição arquitetônica da escola, das salas de aula, dos espaços externos, etc.). O currículo é, assim, um território em crescente disputa (ARROYO, 2013).

As escolas, de maneira alguma podem ser alheias a toda dinâmica cultura da comunidade na qual estão inseridas, pois para conhecer e compreender a gama de significados comuns que acabam por se manifestar nas atitudes e comportamentos da 
comunidade, precisam estar imersas e comprometidas com o contexto local. $\mathrm{O}$ desenvolvimento comunitário, nesse sentido, necessita ser um processo tanto educativo quanto formativo, no qual a comunidade se torna responsável também, já que participa das decisões referentes as resoluções de problemas comuns vivenciados. As escolas, vistas como agentes sociais nesse processo, não podem se responsabilizar integralmente pelo desenvolvimento dos sujeitos, portanto precisa contar com o apoio de todos e colaboração da comunidade social.

\section{Os caminhos da pesquisa: a construção a partir do olhar dialético da realidade}

Considerando que as os professores são os principais mediadores entre os conhecimentos curriculares e a realidade dos estudantes, assim como suas "vozes, experiências e opiniões [...] são os elementos vitais da própria mudança" (HAGEMEYER, 2004, p. 83), o foco da pesquisa foram os professores. Neste sentido, optou-se por trabalhar com os professores das escolas da Ilha que relataram, em um questionário exploratório aplicado no início da investigação, desenvolverem ou terem desenvolvido atividades de Educação Ambiental. Além disso, considerou-se também a organização curricular diferenciada ${ }^{3}$ que os colégios apresentam como um potencial para a inserção da questão ambiental, assim como o interesse da pesquisadora na formação de professores para os Anos Finais do Ensino Fundamental e Médio.

A dialética, vista como um método de interpretação dinâmica e de totalidade da realidade (LOUREIRO, 2012; FREIRE, 1979), proporcionou compreender que os fenômenos são considerados sempre em relação com os contextos (social, político, econômico, cultural, etc.) aos quais o objeto está em movimento. Tristão (2007) colabora com esse entendimento quando diz que a própria natureza da Educação Ambiental, que encara a realidade como processo e não como algo estático, remete-nos a um tipo de pesquisa em que se estabelece uma integração entre o pesquisador, os sujeitos da pesquisa e o próprio meio ambiente, com as propostas de modificação da realidade pesquisada com intervenções do pesquisador. Fazer ciência em uma perspectiva dialética é, portanto, assumir que o próprio conhecimento, construído historicamente, está impregnado de ideologias. É assumir também que cada currículo é uma decisão, portanto, de quem o constrói, e esse processo não se dá sem que haja espaço para outros tantos "mundos nãoditos".

\footnotetext{
${ }^{3}$ As escolas das ilhas do litoral do Paraná têm uma proposta de organização curricular diferenciada desde 2010, por áreas do conhecimento.
}

Rev. Eletrônica Mestr. Educ. Ambient. Rio Grande, Edição especial XVI Encontro Paranaense de Educação Ambiental, p. 132-149, set. 2017. E-ISSN 1517-1256 
Optou-se por dar a investigação um enfoque qualitativo, já que é consenso entre os autores que abordam a questão da pesquisa como construção social (TRIVIÑOS, 2010; LUDKE; ANDRÉ, 1986; ANDRÉ, 2013, entre outros) que existe uma relação dinâmica entre o mundo real e o sujeito, ou, em outras palavras, há uma ligação inseparável entre o mundo objetivo e a subjetividade do sujeito. Nesse ponto de vista, há elementos que compõe essa relação que não são possíveis de serem transformados em números. Dessa forma, esse enfoque foi considerado o mais coerente, já que as práticas pedagógicas dos professores em relação a Educação Ambiental são marcadas por visões de mundo, valores, percepções e concepções que se relacionam cotidianamente entre si.

A partir dessas considerações, delineou-se tanto para Coleta quanto para Análise dos dados a técnica da triangulação (TRIVIÑOS, 2010; MINAYO, 2005; MARCONDES; BRISOLA, 2014), entendendo que assim é possível que se tenha maior credibilidade dos resultados da pesquisa. Nesse sentido, o principal objetivo dessa metodologia visa contribuir não somente na análise do objeto em várias perspectivas, mas enriquecer o olhar e as dimensões que o compõe, validando com maior rigor as pesquisas qualitativas.

Assim, optou-se nesse estudo por trabalhar com três técnicas para Coleta de dados, visto como complementaridades e não como dicotomias (DUARTE, 2004):

$\rightarrow$ Entrevista semiestruturada, escolhida como técnica central, utilizada como forma de conhecer quais são as percepções sobre a Educação Ambiental que os professores apresentam e como organizam/realizam as práticas pedagógicas de Educação Ambiental;

$\rightarrow$ Observação participante, que permite que o pesquisador se aproxime da perspectiva e percepções dos sujeitos investigados, assim como enxergue novos problemas ou potencialidades em torno do objeto estudado. As observações se constituíram em momentos de participação efetiva nos colégios, e os laços que foram se constituindo entre a pesquisadora e os professores estão se consolidando com algumas perspectivas de parcerias futuras;

$\rightarrow$ Grupos de discussão com os professores entrevistados que já trabalharam nos dois colégios, a fim não somente de confirmar as opiniões individuais obtidas nas entrevistas, mas o discurso coletivo dos envolvidos, tanto em relação aos significados atribuídos a Educação Ambiental quanto ao desenvolvimento local da Ilha, além de levantar quais são os principais desafios e potencialidades encontradas no cotidiano escolar quanto a execução de práticas pedagógicas de Educação Ambiental. Além disso, foram realizados grupos de discussão com os pais dos estudantes, representando as comunidades, para

Rev. Eletrônica Mestr. Educ. Ambient. Rio Grande, Edição especial XVI Encontro Paranaense de Educação Ambiental, p. 132-149, set. 2017. E-ISSN 1517-1256 
compreender como eles percebem a Educação Ambiental e o papel das escolas no desenvolvimento local. O grupo de discussão com os professores possibilitou que alguns dados fossem comprovados e amadurecidos e ainda que a temática da pesquisa fosse focada. Este grupo se tornou também um espaço de formação, já que foram discutidas questões que são centrais para a Educação Ambiental e que inquietam os professores que participaram, e que se pretende também aprofundar em diálogos futuros. Os grupos com os pais foram bem esclarecedores pois permitiram que se tivesse um retrato - ainda que de maneira inicial - de como eles pensam a Educação Ambiental e o desenvolvimento para a Ilha.

As questões para as entrevistas foram formuladas a partir de cada objetivo específico da pesquisa e organizadas em blocos compostos por quatro categorias de análise: (1) Sentidos da Educação Ambiental, que abrangeram a concepção, as motivações inicias e o objetivo central para as práticas pedagógicas de Educação Ambiental; (2) Prática pedagógica da Educação Ambiental, relacionada ao planejamento, avaliação, conteúdos e saberes envolvidos; (3) Dimensão comunitária da escola, abrangida pela relação entre a escola e a comunidade e as Unidades de Conservação e as comunidades como espaços educativos, e (4) Desafios da práxis da Educação Ambiental na escola, identificando os limites e potencialidades para as práticas pedagógicas.

Para Análise dos dados, foram realizados dois movimentos distintos que se articulam: o primeiro se caracteriza pela análise interna do material e o segundo se caracteriza pela análise propriamente dita. Para tanto, adotou-se três processos interpretativos que dialeticamente se relacionam: (1) pré-análise (transcrição e organização do material coletado); (2) análise contextualizada e triangulada dos dados (diálogo entre a conjuntura macro do campo da Educação Ambiental, autores que tratam da temática específica e dados empíricos), com a finalidade de reconstrução teórica da realidade; (3) síntese-conclusiva, realizada a partir da interpretação da pesquisadora, ou nas palavras de Marcondes e Brisola (2014, p. 206), "uma interpretação das interpretações”.

\section{Desafios da práxis docente da Educação Ambiental para o desenvolvimento comunitário local na Ilha do Mel/PR}

O litoral do estado do Paraná tem a maior área contínua de Mata Atlântica ainda preservada do país, tendo como fundo as elevações da Serra do Mar até a região costeira. Apesar de sua rica biodiversidade, o ecossistema da Mata Atlântica é o mais ameaçado do Brasil e o segundo do mundo, fato que resultou na criação de diversas Unidades de 
Conservação na região. A Ilha do Mel foi uma dessas regiões, e em 1982, percebendo a potencialidade da região para o turismo, com vistas à conservação da ilha, foi criada a Estação Ecológica da Ilha do Mel, representando $80 \%$ da área da região. A porção sul da Ilha, com seu ambiente composto por costões rochosos e com grande riqueza históricocultural, teve seu espaço ordenado tardiamente a partir da criação do Parque Estadual, em 2002. No seu entorno estão as duas principais comunidades: Brasília e Encantadas, com uma população de mais de 1000 habitantes (IBGE, 2010).

Schena (2006), que investigou as mudanças e permanências sociais, culturais, econômicas e ambientais desencadeadas na Ilha pelo desenvolvimento do turismo, entende que as Unidades de Conservação foram criadas tardiamente, após a intensa e desordenada ocupação e uso do solo, quando muitas pessoas "de fora" já haviam comprado as propriedades dos moradores nativos a um baixo custo e construído muitas pousadas e campings na região. Nessa perspectiva, alertam Gonzaga, Denkewicz e Prado (2014) em seu estudo que a implantação das Unidades de Conservação na Ilha também promoveu forte impacto sobre as atividades econômicas tradicionais (pesca e roça artesanal) das comunidades caiçaras nativas e além disso consolidou o turismo como a principal atividade econômica do local.

Atualmente, Telles (2007) sinaliza que a Ilha passa por um momento de problemáticas socioambientais evidentes, diretamente relacionadas a exploração turística. A essa problemática somam-se também a falta de fiscalização nas ações restritivas e não consideração das comunidades nos processos decisórios. Trazendo ainda as contribuições do autor, não há participação dos diferentes atores sociais e o esclarecimento quanto aos seus respectivos benefícios e responsabilidades nas diferentes fases do processo de desenvolvimento da região.

É visível, portanto, a fragmentação e a ausência de articulação das comunidades, fato que tornou a sociedade local vulnerável à tomada de decisões externas (TELLES, 2007; PIERRI; KIM, 2008). Ou seja, a participação da comunidade não se constitui em um instrumento para a interferência nos aspectos da gestão. Essa configuração influencia diretamente na autoestima dos sujeitos que ali convivem, trazendo consequências como a pobreza generalizada, o consumo de drogas, entre outras.

Aliada a essa questão está a defasagem educacional da Ilha. A precariedade das condições (oferta, acesso e qualidade) em que se estruturou a educação básica na região, assim como a baixa oferta de capacitação profissional específica, acabaram por reproduzir as desvantagens dos nativos em relação as pessoas de fora, ampliando a diferenciação 
social na Ilha: o desnível educacional e de poder aquisitivo muitas vezes acarreta em conflitos advindos principalmente da concorrência pelas atividades comerciais de exploração do turismo.

$\mathrm{Na}$ Ilha do Mel a primeira escola de educação formal foi ativada em 1982. Até o ano de 2003, a escolarização esteve limitada até a $4^{\circ}$ série do ensino fundamental. Antes disso, para cursar os anos finais do ensino fundamental e o ensino médio, os estudantes precisavam se deslocar ao continente, pegando a barca todos os dias até a cidade mais próxima (Pontal do Sul), salvo quando as condições climáticas não permitiam, fato que contribuía ainda mais para a evasão escolar. Atualmente há oferta de toda a educação básica na Ilha, incluindo a Educação de Jovens e Adultos, tanto em Encantadas quanto em Brasília.

Entretanto, há diversos e complexos problemas enfrentados cotidianamente pelos professores, tais como: precariedade do espaço físico das escolas, como por exemplo espaços pequenos e sem manutenção, falta de materiais e de internet, falta de laboratórios e bibliotecas, entre outros; alta rotatividade de professores, principalmente por conta das situações de trabalho (transporte e estadia), visto que a maioria, além de não serem moradores da região, são contratados temporariamente a cada semestre via Processo Seletivo Simplificado (PSS); dualidade administrativa, ou seja, coexistência no mesmo espaço/prédio das escolas municipais e dos colégios estaduais, situação que gera diversos conflitos cotidianos; falta de apoio pedagógico, administrativo e de manutenção dos órgãos competentes (Secretarias de Educação); falta de participação da comunidade na escola, entre outros.

Verifica-se precariedade no que se refere as condições principalmente de trabalho dos professores, que refletem na impossibilidade de ações mais efetivas, contínuas, interdisciplinares e, especialmente, um reconhecimento mais profundo - e crítico - da realidade dos estudantes, trazendo diversos desafios a potencialização da Educação Ambiental nos colégios. Esse é um dos maiores problemas históricos da Educação do Campo: o fato de que os professores não fazem parte da comunidade e, em grande parte das vezes, não conseguem fazer uma relação mais consistente e coerente dos conteúdos curriculares com a prática social dos estudantes, reproduzindo a lógica da descontextualização dos sentidos da escola para essas populações, que foram invadidas culturalmente pela lógica do sistema capitalista.

Constatou-se que além de não apresentar condições suficientes (estrutura, materiais e formação) para um trabalho docente mais efetivo de Educação Ambiental, grande parte 
dos professores, por conta da situação temporária, não conseguem avançar e aprofundar nem no entendimento das dinâmicas que a Ilha vive, nem na construção de sentidos que gerem sentimento de pertencimento ao lugar. Nesse caso, é preciso que as mantenedoras dos colégios realizem um diagnóstico mais aprofundado sobre as reais necessidades estruturais e formativas dos professores em casos como os vivenciados na Ilha do Mel. Ainda, há necessidade de uma escuta mais sensível por parte dos colégios para as demandas das comunidades, dos estudantes e das instituições parceiras educativas formais e não-formais.

É preciso nesse sentido reorganizar tempos e espaços escolares para isso, o que depende diretamente da abertura da gestão, o que foi evidenciado também nos depoimentos dos professores, que sentiram diferenças nesse aspecto na gestão dos dois colégios. Há de se abrir as escolas às comunidades, para que elas se apropriem do que é de seu direito: o espaço público. Nesse sentido, é preciso ver as comunidades como espaços educativos e, mais que isso, que sejam parceiras, e porque não protagonistas, na condução e decisão dos processos escolares.

Ao olhar dos professores, o papel da escola para o desenvolvimento local é visto a partir de três tendências: (1) Parte da realidade e espaço de fortalecimento da comunidade - papel atrelado a mobilização, é o "ponto de apoio" da comunidade; (2) Formadora de futuras gerações e de cidadania - em outras palavras, a escola vista como formadora de personalidades e de comportamento, e a cidadania no sentido apresentado tem a ver com a identificação dos estudantes com a dinâmica comunitária da qual fazem parte; (3) Espaço de disseminação de informações e conhecimentos sistematizados - a escola é a instituição que oferece as melhores informações sobre as questões ambientais e ainda configura-se como uma prática intencionada e planejada durante grande parte da formação dos sujeitos. Tendo em vista os aspectos observados, pode-se afirmar que há preocupação por parte de todos os professores em contribuir para melhorar a qualidade de vida das comunidades.

O olhar dos pais e mães foi essencial para identificar as contribuições da escola para o desenvolvimento local da região. Primeiramente, constatou-se que todos eles relacionam a Educação Ambiental à preservação ambiental e, nesse sentido, a entendem como necessária à continuidade das atividades turísticas que estão atreladas aos atributos naturais da Ilha. Demostram que se sentem privilegiados de morar na Ilha por conta de suas belezas, mas apresentam-se descontentes com as restrições impostas pelas Unidades de Conservação. A escola, para eles, tem como papel principal a de ofertar capacitação para os estudantes e as comunidades, a fim de que consigam melhores oportunidades de 
empregos e de geração de renda. Um ponto importante para a discussão da presente pesquisa foi a constatação que as ações de Educação Ambiental, segundo as famílias, devem partir dos estudantes e não dos colégios, uma vez que eles desacreditam das instituições que fazem parte da sua dinâmica comunitária, como é o caso da escola.

A escola nesse sentido precisa ser vista como possibilidade de fixação, ou seja, educar para o estudante ficar, não para sair da Ilha. Constata-se que o ecoturismo, que é o tipo de desenvolvimento que propõem os planos de manejo das Unidades de Conservação da Ilha, pode possibilitar um desenvolvimento local para a região que permita que a região atinja uma sustentabilidade mais profunda e adequada ao contexto particular das ilhas, no sentido de que sejam proporcionados aos turistas experiências simultâneas de preservação dos recursos naturais e culturais. Para isso é necessário que se realizem mais do que ações que procurem somente controlar o número de visitantes no local, mas investimentos nos serviços de saneamento básico, por exemplo, que é um dos maiores problemas ambientais da região, já que sua população aumenta consideravelmente nas épocas de alta temporada. Importante destacar que o ecoturismo dá particular atenção ao uso do componente educativo, voltado para o turista e também para a população local e para os agentes turísticos que atuam nas Unidades. O fato é que o que ocorre na realidade são traços de um turismo de massa, que nega os problemas ambientais, sociais e culturais que as atividades turísticas podem trazer para a região e que geram benefícios que não se revertem para as comunidades locais, acentuando a pobreza e melhores condições de vida para as mesmas.

As famílias e os professores concordam que os estudantes e a comunidade não se interessam pelas questões ambientais da região e que trabalhar com a Educação Ambiental é algo complicado: as comunidades não entendem o porquê das restrições impostas pelas Unidades de Conservação e não concordam que elas sejam as mesmas para todos os moradores, já que o impacto ambiental que causam são muito menores do que os donos de grandes pousadas. Como eles salientaram, enquanto para alguns as restrições são impostas de maneira irredutível, para outros ela é flexível e facilitada. Ainda, quando há possibilidades de participação das comunidades em espaços de decisão coletiva, grande parte das vezes elas são representadas por sujeitos que não consideram suas reais necessidades e expectativas.

\section{Considerações finais: a busca pelas possíveis relações}

$\mathrm{Na}$ busca pelas possíveis relações entre Educação Ambiental, Currículo e Desenvolvimento comunitário local, constatou-se que a Educação Ambiental, quando 
considera em sua prática educativa escolar que sua dimensão comunitária contribui para recriar os vínculos de pertencimento dos sujeitos ao território que vivem, para que se reconheçam como integrantes de uma comunidade e para que reconstruam a sua identidade com o local em que vivem, pode contribuir para seu desenvolvimento e consequentemente para sua transformação social.

Ao professor, em primeiro lugar, caberia o papel de contribuir e apoiar o estudante a fazer uma leitura histórica da realidade mais ampla. Isso implica em assumir uma prática pedagógica que tenha como ponto de partida a noção de como a sociedade está estruturada no contexto local e como esta realidade se configura na própria escola. Não só isto, mas na necessidade de compreensão das relações que coexistem nela, nas relações sociais específicas que compõe a vida na Ilha do Mel, nas determinações veladas, que privam os sujeitos de se organizarem para a transformação necessária. Este processo crítico de inserção do professor na dinâmica comunitária requalifica sua prática social, já que permite que o conhecimento da realidade se torne mais coerente, consistente e, portanto, promova mudanças.

Afirmar que à escola cabe o papel de assegurar aos estudantes o acesso ao conhecimento sistematizado, já que de outra maneira eles não teriam acesso a ele, é também assumir que esse conhecimento precisa ser pensado na perspectiva do desvelamento da realidade. O objetivo da prática educativa é, nesse sentido, contribuir para que os estudantes se articulem, se organizem, cultivem e valorizem sua cultura, os saberes, as identidades, os valores e as memórias que circundam sua comunidade, assumindo-se como sujeitos de transformação. É ver os estudantes com outros olhos, não como seres passivos e subordinados, mas ativos, que em diálogo com a comunidade possam assumir um comando coletivo das suas escolas, enfim, que possam transformar o conhecimento apreendido em ação. Coloca-se como objetivo mais amplo a construção de um novo modelo de desenvolvimento, local e comunitário, que possibilite fazer da Ilha um espaço mais amplo de formação e cidadania.

A Educação Ambiental, no contexto pesquisado, se baseou na perspectiva de uma ação diferenciada, específica, alternativa, comprometida com o empoderamento comunitário, que promova a democratização dos espaços de participação, que veicule saberes significativos e possibilite oportunidades reais e canais de comunicação para que a comunidade consiga romper com as situações e relações que silenciem e paralisem os sujeitos que dela fazem parte. Que colabore para a redução da pobreza e para a conservação dos bens naturais e da biodiversidade e que apresente uma proposta 
educacional alternativa para o desenvolvimento de comunidades mais responsáveis, sustentáveis e porque não dizer, mais felizes.

\section{Referências}

ANDRÉ, Marli. O que é um Estudo de Caso Qualitativo em Educação? Revista da FAEEBA - Educação e Contemporaneidade, Salvador, v. 22, n. 40, p. 95-103, jul./dez. 2013.

ANDREOLI, Vanessa Marion. A Educação Ambiental no contexto dos colégios estaduais da Ilha do Mel/PR: Currículo, ação docente e desenvolvimento comunitário local. Tese (Doutorado em Educação) - Universidade Federal do Paraná. Programa de PósGraduação em Educação - Curitiba, 2016. 370 f.

ARROYO, Miguel. Currículo, território em disputa. 5 ed. Petrópolis, RJ: Vozes, 2013. BRANDÃO, Carlos Rodrigues. O Que é Educação. São Paulo: Editora Brasiliense, 1981.

CALDART, Roseli Salete et al. (org.). Caminhos para transformação da escola: reflexões desde práticas pedagógicas da Licenciatura em Educação do Campo. São Paulo: Expressão Popular, 2012. p. 127-154.

CARVALHO, Vilson Sérgio. Educação ambiental e desenvolvimento comunitário. Rio de Janeiro/RJ: WAK, 2002.

DIEGUES, Antonio Carlos. Desenvolvimento sustentável ou sociedades sustentáveis: da crítica dos modelos aos novos paradigmas. São Paulo em perspectiva, 6 (1-2): 22- 29, janeiro/junho, 1992. Disponível em: http://produtos.seade.gov.br/produtos/spp/v06n0102/v06n01-02_05.pdf. Acesso em 23/05/2016.

\section{. A Educação Ambiental e a Questão das Áreas Naturais Protegidas.}

São Paulo, NUPAUB-USP, 2010.

DUARTE, Rosália. Entrevistas em pesquisas qualitativas. Educar, Curitiba, n. 24, p. 213-225. Curitiba: Editora UFPR, 2004.

FREIRE, Paulo. Conscientização: Teoria e Prática da Libertação. Uma Introdução ao Pensamento de Paulo Freire. São Paulo: Cortez \& Moraes, 1979.

Ação cultural para a liberdade. 5 ed., Rio de Janeiro, Paz e Terra. 1981.

GÓMEZ, José António Caride; FREITAS, Orlando Manuel Pereira de; CALLEJAS, Germán Vargas. Educação e Desenvolvimento Comunitário Local: perspectivas pedagógicas e sociais da sustentabilidade. Porto: Profedições, 2007.

GONZAGA, Carlos Alberto Marçal; DENKEWICZ; Patrícia; PRADO, Keyla Cristina Pereira. Unidades de Conservação, ecoturismo e conflitos socioambientais na Ilha do Mel, PR, Brasil. Gestão de processos, sustentabilidade e responsabilidade social, 2014, v.7, n¹. p. 61-67. Disponível em:

http://www.admpg.com.br/revista2014_1/Artigos/Artigo\%207\%20\%20v.7\%20n.1\%20on \%20line.pdf. Acessado em: 24/03/2015.

HAGEMEYER, Regina Cely de Campos. Dilemas e desafios da função docente na sociedade atual: os sentidos da mudança. Revista Educar, Curitiba, n. 24, p. 67-85, 2004. Editora UFPR. Disponível em:

http://unesdoc.unesco.org/images/0015/001545/154576por.pdf. Acessado em: 20/08/2016.

Rev. Eletrônica Mestr. Educ. Ambient. Rio Grande, Edição especial XVI Encontro Paranaense de Educação Ambiental, p. 132-149, set. 2017. E-ISSN 1517-1256 
LOPES, Alice Ribeiro Casimiro. Conhecimento escolar: ciência e cotidiano. Rio de Janeiro: EdUERJ, 1999.

LOUREIRO, Carlos Frederico Bernardo; Trajetória e Fundamentos da Educação Ambiental. 4 ed. São Paulo: Cortez, 2012.

LUDKE, Menga; ANDRÉ, Marli. Pesquisa em educação: abordagens qualitativas. São Paulo: Editora Pedagógica e Universitária, 1986.

MARCONDES, Nilsen Aparecida Vieira; BRISOLA, Elisa Maria Andrade. Análise por triangulação de métodos: um referencial para pesquisas qualitativas. Revista Univap. São José dos Campos/SP, Brasil, v. 20, n. 35, jul.2014.

PIERRI, Naína; KIM, Milena Kiatkoski. A sustentabilidade social como condição para a conservação. O caso da Ilha do Mel (Paraná, Brasil). IV ENANPPAS - Encontro da Associação Nacional de Pesquisa e Pós-Graduação em Ambiente e Sociedade. Junho de 2008. Disponível em: http://www.anppas.org.br/encontro4/cd/ARQUIVOS/GT16. Acessado em: 23/09/2016.

MINAYO, Maria Cecília de Souza. (org.). Introdução. In: MINAYO, Maria Cecília de Souza; ASSIS, Simone Gonçalves; SOUZA, Edinilsa Ramos (Orgs.). Avaliação por triangulação de métodos: Abordagem de Programas Sociais. Rio de Janeiro: Fiocruz, 2005 .

PORTO-GONÇALVES, Carlos Walter. Os (Des)Caminhos do meio Ambiente. 14 ed. São Paulo. Contexto, 2008. Revista Eletrônica Mestrado Educação Ambiental. v. 30, n. 1, p. 83 - 101, jan./ jun. 2013.

SAUVÉ, Lucie. Educação Ambiental: possibilidades e limitações. In: Educação e Pesquisa. São Paulo, v.31, n.2, p.317-322, maio/ago, 2005.

Viver juntos em nossa Terra: Desafios contemporâneos da educação ambiental. Revista Contrapontos - Eletrônica, Vol. 16 - n. 2 - Itajaí, mai-ago 2016. Disponível em: http://siaiap32.univali.br/seer/index.php/rc/article/view/8697/pdf. Acessado em: 21/02/2016.

SAVIANI, Dermeval. Pedagogia Histórico-crítica: primeiras aproximações. 8 ed. São Paulo: Cortez Editora e Editora Autores Associados, 2003.

SCHENA, Fernando. Turismo, estado, sociabilidades e mudança: uma etnografia da Vila de Encantadas, Ilha do Mel. Dissertação (Mestrado) - Setor de Ciências Humanas, Letras e Artes - UFPR. Curitiba, 2006. 107 p.

TELLES, Daniel Hauer Queiroz. Análise sobre a situação socioambiental e atividade turística da Vila de Encantadas, Ilha Do Mel - Paraná. (Dissertação). Pós-Graduação em Geografia, Setor de Ciências da Terra, Universidade Federal do Paraná. Curitiba, 2007.

TORALES-CAMPOS, Marília Andrade. A inserção da Educação Ambiental nos currículos escolares e o papel dos professores: da ação escolar à ação educativocomunitária como compromisso político-pedagógico. Revista Eletrônica do Mestrado em Educação Ambiental, Rio Grande/RS, v. especial, p. 1-17, mar. 2013.

TOZONI-REIS, Marília Freitas de; CAMPOS, Luciana Maria Lunardi. Educação ambiental escolar, formação humana e formação de professores: articulações necessárias. Educar em Revista, Curitiba, Brasil, Edição Especial n. 3/2014, p. 145-162. Editora UFPR.

Rev. Eletrônica Mestr. Educ. Ambient. Rio Grande, Edição especial XVI Encontro Paranaense de Educação Ambiental, p. 132-149, set. 2017. E-ISSN 1517-1256 
TREIN, Eunice Schilling. A educação ambiental crítica: crítica de que? In: Rev. Contemporânea de Educação, vol. 7, n. 14, agosto/dezembro de 2012.

TRISTÃO, Martha. A educação ambiental e os contextos formativos na transição de paradigmas. $33^{\circ}$ Reunião Nacional da ANPED. Caxambu, MG, 07 a 10/out/ 2007.

TRIVIÑOS, Augusto Nibaldo Silva. Introdução à pesquisa em ciências sociais: a pesquisa qualitativa em educação. 1 ed. 19 reimpr. São Paulo: Atlas, 2010.

VASCONCELLOS, Celso dos Santos. Currículo: a atividade humana como princípio educativo. 3 ed. São Paulo: Libertad, 2011.

WITT, Julia Rovena; LOUREIRO, Carlos Frederico Bernardo; ANELLO, Lucia de Fatima Socoowski de. Vivências em Educação Ambiental em unidades de conservação:

caminhantes na trilha da mudança. Rev. Eletrônica Mestrado em Educação Ambiental. V. 30, n. 1, p. 83 - 101, jan./ jun. 2013.

Submetido em: 31-07-2017.

Publicado em: 30-09-2017.

Rev. Eletrônica Mestr. Educ. Ambient. Rio Grande, Edição especial XVI Encontro Paranaense de Educação Ambiental, p. 132-149, set. 2017. E-ISSN 1517-1256 